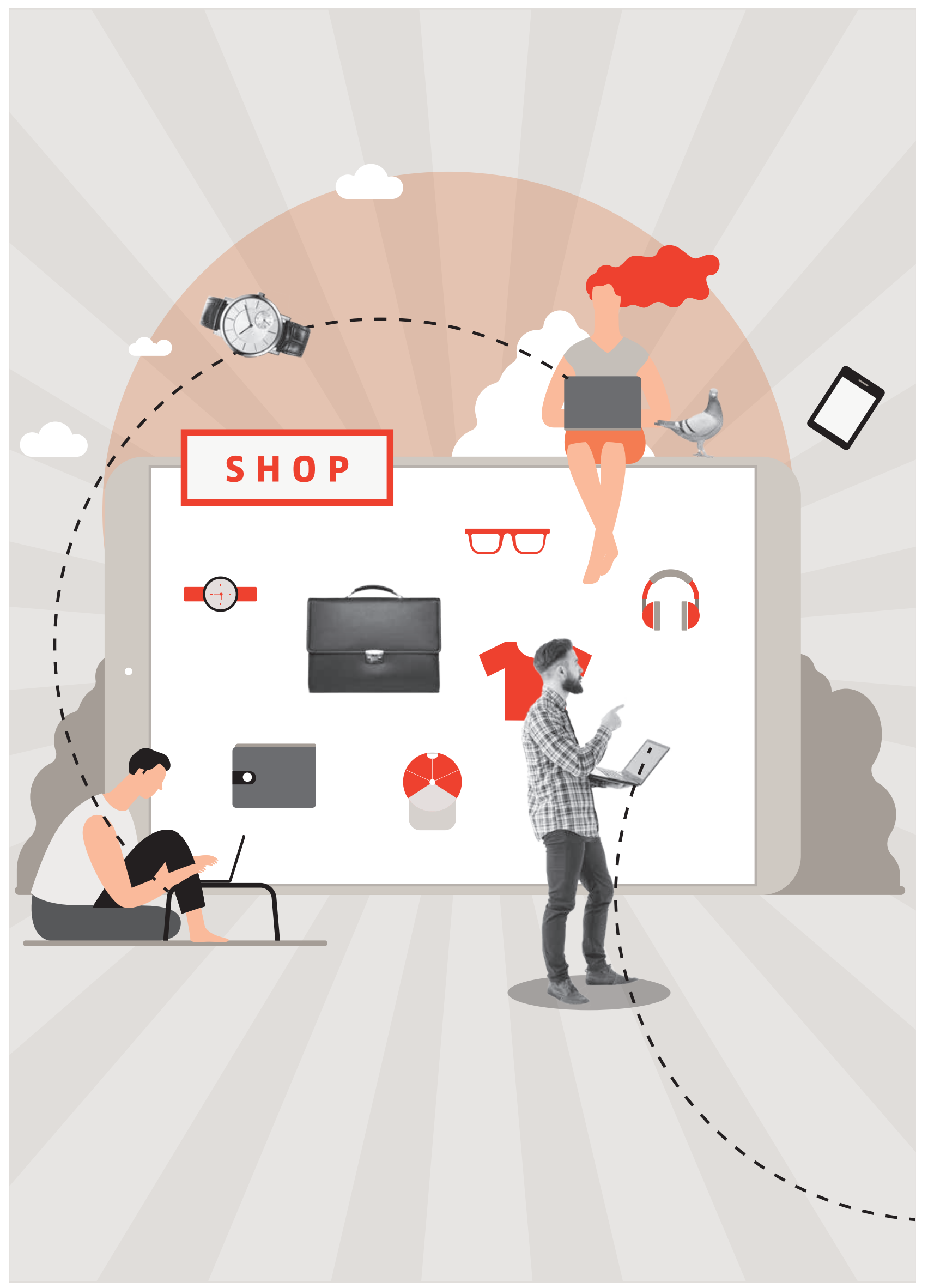




\title{
Digitalized Interactive Platforms: Turning Goods and Services into Retail Co-Creation Experiences
}

\author{
Venkat Ramaswamy and Kerimcan Ozcan
}

\section{KEYWORDS}

Offerings, Digitalized Interactive Platforms, Interactional Value Creation, Omnichannel Store Environments, Smart Retailing, Retail Ecosystems

THE AUTHORS

Venkat Ramaswamy

Hallman Fellow Electronic Business and Professor of Marketing, Ross School of Business, University of Michigan; Ann Arbor, MI, USA venkatr@umich.edu

\section{Kerimcan Ozcan}

Assistant Professor of Marketing, Marywood University, Scranton, PA, USA kerimcan.ozcan@gmail.com
Co-creation replaces distinct roles of retailers and shoppers /// Over the past decade, the digitalized technology revolution has transformed retail offerings. Traditionally, retailers and shoppers were seen as having distinct roles in the process of retail value creation. Shoppers had a stake, but retailers viewed them as being largely passive and docile recipients of retailers' offers. With the rise of digital technologies, however, shopping has morphed from purchasing products, through receiving services, to having experiences and, ultimately, to transforming a lifestyle.

Retailing has become a field of value co-creation. Instead of offerings "having value" in the traditional sense, retailers now offer the means for continuously "creating value" through interactions. Offerings are no longer finished, but the creation of value continues in a joint space between consumers and their social networks and companies with their associated organizational ecosystems. Shoppers co-create and contribute through their different views of the created value and through their specific interactions on digital and mobile devices and in social networks. Often parts of the process happen away from retailers' own premises and increasingly move into shoppers' environments.

Digitalized interactive retail platforms: Joint spaces for co-creation /// Consequently, retailers are increasingly faced with the challenge of purposefully designing their offerings as digital interactive platforms (DIPs) for interactional value creation. This movement spans the retail landscape from omnichannel store environments and smartconnected retailing to entire retail ecosystems. Box 1 highlights the conceptual framework of DIPs in retailing and Box 


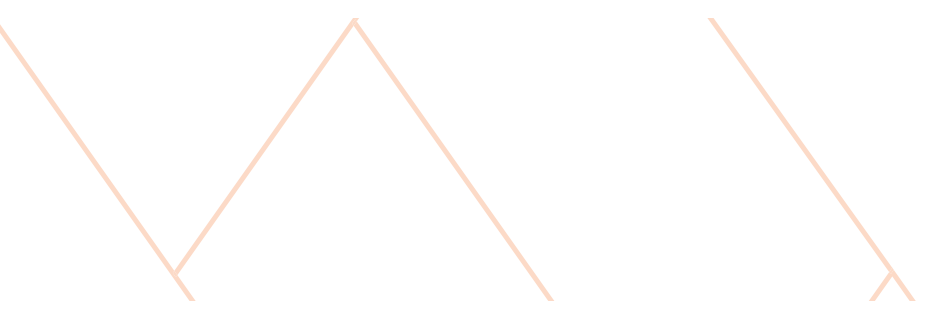

2 presents a brief outline of Apple's digitalized interactive retailing platform and retailing ecosystem. Other brands that have successfully developed their own DIPs are Starbucks, Burberry and - of course - Amazon, and we will present how these brands have transformed their retailing experience.

How Starbucks manages omnichannel store environments /// Consider the case of Starbucks' retail stores and its Starbucks app. The pre-transaction environment involves a DIP that includes menu boards and a showcase of food items, along with one's favorites and past purchase history. The transaction environment consists of a DIP entailing an order processing system integrated with purchase-based rewards and payment options, and estimated time of pickup. In the digitalized physical environments of Starbucks' as a "third place," the customer becomes part of an assemblage of tables and chairs made from ecologically recycled and increasingly locally sourced wood that connects with environmentally conscious customers. The music -streamed by Starbucks partner Spotify - the complimentary WiFi service, lighting, the artwork showcasing local artists, and other persons in the store round out environments of experiences. There is also the scope for individuals to define their own preferred consumption contexts and to enjoy and shape different kinds of personalized Starbucks experiences.

\section{How Burberry encourages smart, connected retailing}

/// The fashion retailer Burberry has brought together its customer portal, social marketing, its supply chain and the Burberry world of fashion, together with the retail experience, social product offerings, custom mobile apps, insights and analysis, in a unified retail enterprise architecture. In its flagship retail stores the retail experience has changed through several enabling technologies deployed throughout the store to engage individuals. For instance, a key enabling technology is a radio-frequency ID tagging (RFID) system, which provides both sales associates and customers with immediate access to a rich stream of content when a RFID-tagged item is activated. The content includes up-to-date information on every item, such as what sizes or colors are currently available. This information enables sales associates to spend more time attending personally to a customer, rather than disappearing in the back room to check the stock. The content also includes the heritage of the product, sketches, color swatches and video clips, which customers can view on display units throughout the store.

Customers can visit the store with items saved from their online account. They can make store appointments to check out a new collection and initiate conversations on a variety of lifestyle issues. Employees not only have access to CRM type data, but they can also connect with customers' social media activities, from Facebook comments to Tweets and blog postings. Catwalk shows can be watched live on a huge screen, and customers can participate remotely in fashion shows with a front seat experience and order items in real time directly off the runway. Customers also get to showcase the retail brand's iconic products, such as its trench coat, through a standalone social media platform environment, uploading photos of themselves wearing their trench coats, featured on the site's main page for a short duration. They can also suggest (re)design ideas for products. Burberry, in turn, can experiment with changes to its offerings and test its marketing communications with the Burberry community.

How Amazon leverages its retail ecosystems /// Amazon customers can interact and transact with Amazon retail offerings through online services such as Amazon.com, Amazon Music, Amazon app and Alexa. All services are made more accessible through devices such as Amazon Fire, Echo and Dash and extended through brick-and-mortar operations such as Whole Foods, Amazon Books, Amazon Locker and Amazon Go. Amazon.com itself continues to be a DIP retail offering par excellence. It consists of an assemblage of elements like the 1-click ordering button and the ubiquitous Amazon delivery boxes, and of people like the tens of thousands of Amazon reviewers populating the world's largest and most-up-to-date database of customer reviews. Algorithmic processes power the experience-centric analytics and recommendation engine, and the industry-leading web navigation interface that is continuously iterated to sustain stickier and personalized engagements. "Amazon.com + Echo + Alexa," "Amazon.com + Amazon Books + Amazon app," or "Amazon.com + WholeFoods" can be seen as further assemblages of the focal DIP retail offering coming into relation with other supporting DIPS in the Amazon network.

In each instance, value emerges from joint creation through the contextualized, location-based and dynamic interactions of DIP components activated by particular shoppers, allowing unique engagements. The Amazon network multiplies the value of Amazon.com to shoppers and cannot be controlled and staged by the company on its own. Shoppers, by co-creating with the network, are active stakeholders in defining the interactions, the context of the events that underlie these interactions and what they find meaningful. 
$\{$ Box 1$\}$

\section{INTERACTIONAL VALUE CREATION THROUGH DIGITALIZED INTERACTIVE PLATFORMS (DIPS)}

In a network economy with innovation increasingly based on personalization and co-design of services, offerings as DIPs promote interactive agency in retail environments. A DIP can be described as an evolving digitalized networked arrangement of related physical and digitalized artifacts of persons, increasingly software-enabled processes, and different interfaces such as apps or elements of a store (see Figure 1). Altogether they provide many interactive system environments enacting interactional creation of value.

FIGURE 1:

\section{Retail offering as a DIP, composed of artifacts, persons, processes and interfaces, affording multiple interactive system environments for engaging actors}

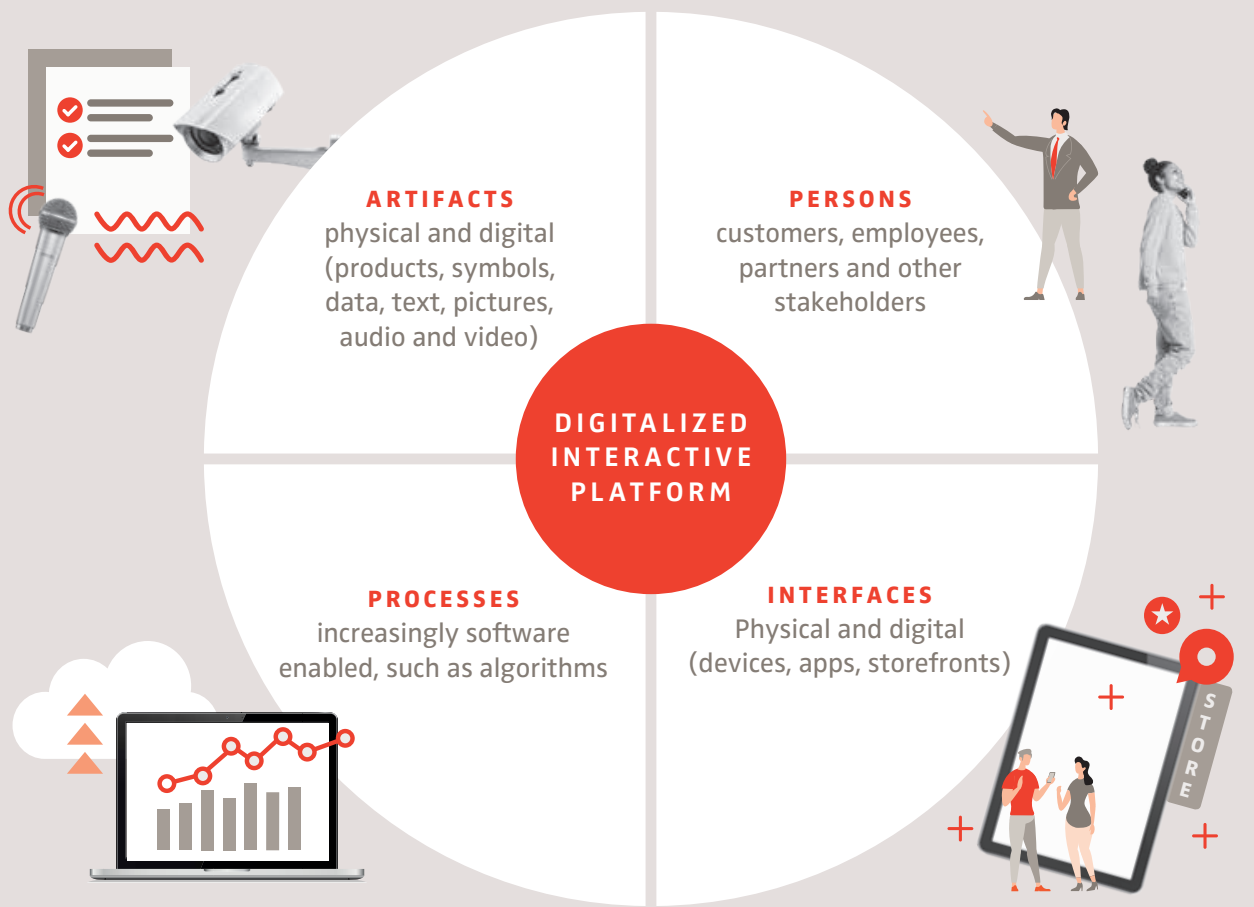

Typically, individuals engage with a retail DIP offering in their particular contexts of interactions with apps or similar components. By delving deeper into the nature of the individual interactions, hidden and untapped sources of value can be revealed. Shoppers get more engaged, and retail managers gain more insights and are able to design ecosystems that allow a more effective creation of "all-win more" outcomes, especially in more profitable ways. 
$\{$ Box 2$\}$

\section{APPLE'S DIGITALIZED INTERACTIVE PLATFORM: THE RETAILING EXPERIENCE RECONFIGURED}

Apple's retail store is a great example of an environment through which DIPs come to life for individuals experiencing the store. Artifacts, employees, processes and interfaces (see Figure 1) are purposefully arranged in a typical Apple store located in a shopping mall or city. The store is territorially and symbolically set apart from all other neighboring shops to convey a museum-like aesthetic. Products on display are not presented as mere commodities with exchange- or use-value but as artifacts intrinsically worthy of playful interaction and enjoyment with full mind-body engagement. Apple's (mobile) devices transport customers to a larger world of play, exploration and discovery of entertainment, productivity and lifestyle media. The virtual possibilities are designed thoughtfully and are neither trivial nor obvious out of the box.

The store as a DIP offering is configured for ordinary people to combat "feature-itis," the common overemphasis by technology companies on the features of products. Instead, Apple is focused on inviting people to play with its products as they would experience them. In the store, employees are equipped, of course, with Apple devices. But more importantly, an internal app allows employees to capture insights from the experience in interactional creation of individuals. This includes employees offering customer support through the Genius Bar after purchase. A digital concierge process, available in both self-service and employee-assisted modes, orients entering customers, directing them to appropriate parts of the store or fixing an appointment at the Genius Bar for walk-ins. With EasyPay as an interface for supporting DIPS, customers can scan the barcodes of accessories in the store, get reviews, ratings and product specs and pay for purchases within the app through Apple Pay in self-checkout fashion.

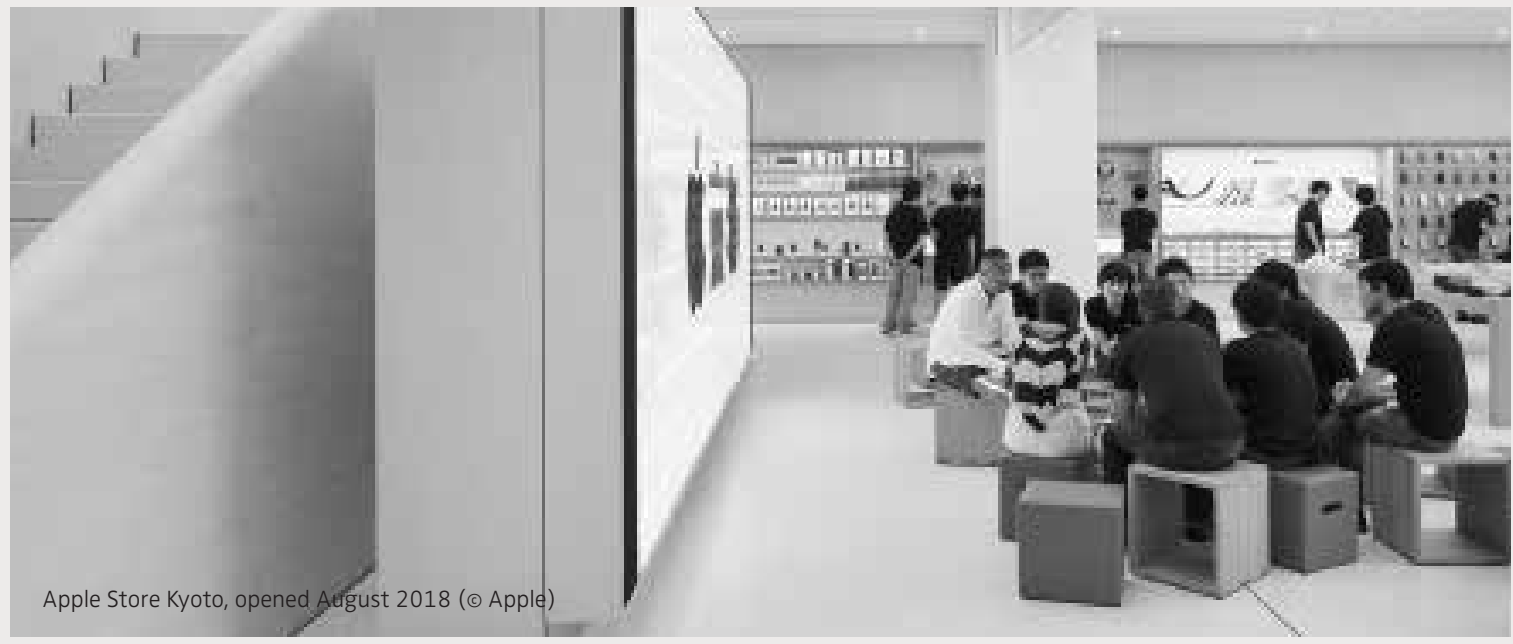

Apple's retail stores and devices, together with the App Store, which is itself a DIP with multiple connective other assemblages entailing books, music, videos and credit card accounts that enable a variety of novel, personalized, co-creational brand experiences. Developers are further stakeholders in Apple's enterprise ecosystem who provide applications for new assemblages of interfaces, artifacts, persons and processes coming together as various kinds of DIP offerings for unique experiences instore and everywhere else. 
〉)

In a connected world, retailers will be successful with hybrid-delivery systems in which consumers can use a range of interface capabilities across multiple channels.

$<<$

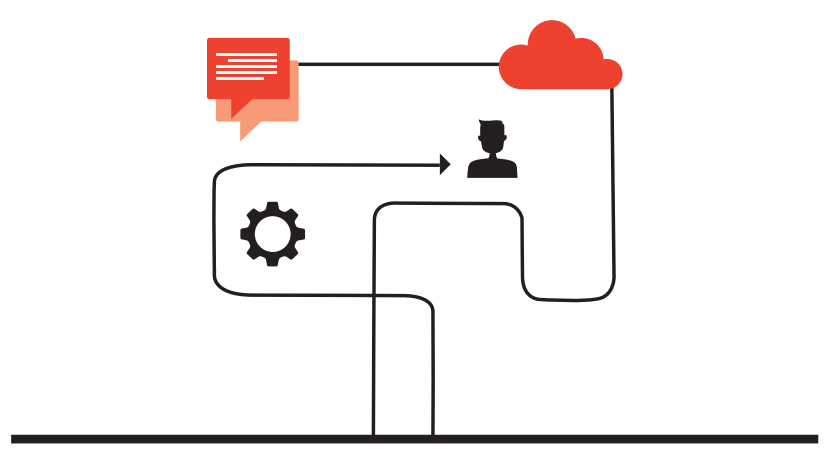

How to be a successful retailer-co-creator /// Based on these retailers' experiences, there are several recommendations for those interested in reinventing retail offers.

$>$ Broaden your view of retailing /// Retailers need to incorporate a broader view of value creation into their operations, encompassing different types of stakeholding individuals in the organizational ecosystem. Shoppers, fashionistas, designers, journalists, enterprise partners and many more can have a distinct role in co-designing environments from the perspective of interactions. They all contribute to meaningful retail experiences, focusing on what different stakeholders value in retail engagements, and to better managing a retailer's relationships by tapping into the knowledge and skills of all individuals, both personally and as communities.

$>$ Enable DIPs for internal and external activities /// DIPs of engagement in retail activities entail digitalized networked arrangements. They need to be designed around activities such as connecting with customers, employees, partners or any other stakeholders, innovating/marketing offerings, customer service/ support and activities of collectives such as brand/ user communities, whether self-organized or otherwise.
> Integrate physical and digital environments /// Technological innovations such as IOT, virtual or augmented reality, GPS and RFID tracking, Al, and robots/drones/driverless vehicles are already changing the face of commerce, equipping both consumers and retailers with new capabilities in decision-making, analytics, traffic flow and customer experience management. Advanced technologies on mobile devices, social networks and in-store solutions are fusing touch-and-feel information in physical retail with online content in e-commerce in smart, connected ways. In a connected world, retailers will be successful with hybriddelivery systems in which consumers can use a range of interface technologies across multiple channels. Being able to interact with informational content, human actors and technical resources at different stages of the decision making and shopping processes will enable rewarding shopping experiences for customers and retailers alike.

I.

\section{FURTHER READINGS}

Ramaswamy, Venkat and Ozcan, Kerimcan (2018):

"Offerings as Digitalized Interactive Platforms:

A Conceptual Framework and Implications”, Journal of Marketing, Vol. 82 (4), 19-31.

Ramaswamy, Venkat and Ozcan, Kerimcan (2014):

“The Co-Creation Paradigm", Stanford, CA: Stanford University Press.

Ramaswamy, Venkat and Gouillart, Francis J. (2010):

"The Power of Co-Creation:

Build It with Themto Boost Growth, Productivity, and Profits", New York:

The Free Press.

Prahalad, C. K. and Ramaswamy, Venkat (2004):

"The Future of Competition:

Co-Creating Unique Value with Customers," Boston: Harvard Business School Press. 